\title{
Genome-Wide Association Study of Resistance to Xanthomonas gardneri in the USDA Pepper (Capsicum) Collection
}

\author{
Neha Potnis, ${ }^{1,2}$ Sandra E. Branham, ${ }^{2}$ Jeffery B. Jones, ${ }^{3}$ and W. Patrick Wechter ${ }^{2, \dagger}$ \\ ${ }^{1}$ Department of Entomology and Plant Pathology, Auburn University, Auburn, AL \\ 2 U.S. Vegetable Laboratory, U.S. Department of Agriculture Agricultural Research Service, Charleston, SC \\ ${ }^{3}$ Department of Plant Pathology, University of Florida, Gainesville, FL \\ Accepted for publication 12 February 2019.
}

\begin{abstract}
Bacterial spot Xanthomonas species cause significant disease outbreaks on tomato and pepper in tropical and subtropical regions throughout the world. Host resistance has been one of the key components of integrated disease management approaches to mitigate plant pathogens. Although a number of resistance genes have been identified in pepper against bacterial spot xanthomonads, emergence of bacterial spot pathogen variants capable of overcoming these sources and changing pathogen distributions reinforce the importance of identifying novel candidates to incorporate into breeding programs. We conducted a genome-wide association study (GWAS) on a diverse U.S. Department of Agriculture collection of pepper germplasm

including different species of Capsicum to identify novel sources of disease resistance against a highly virulent $X$. gardneri strain isolated from a recent outbreak. GWAS identified highly significant single nucleotide polymorphisms associated with defoliation in response to infection with $X$. gardneri. Functionally relevant candidate genes encoded products involved in disease resistance/susceptibility, hormone signaling, and basal resistance against multiple pathogens in various host-pathogen systems. The $X$. gardneriresistant genotypes and quantitative trait loci identified in this study provide alleles that could be used for a resistance gene pyramiding effort against different species of bacterial spot xanthomonads in pepper.
\end{abstract}

Bell and chili peppers (Capsicum spp.) are significant economic crops grown throughout the world. In 2016, the U.S. Department of Agriculture (USDA) estimated bell pepper production at 15.6 million pounds grown on 46,300 acres and valued at more than $\$ 735$ million (NASS 2017). Bacterial spot of peppers is one of the most devastating and difficult to manage diseases on peppers over the past several decades (Jones et al. 2004; Obradovic et al. 2008). Bacterial spot symptoms are seen on aboveground plant parts of pepper and include necrotic lesions that expand upon disease progression and result in large necrotic areas. The disease can cause severe defoliation, resulting in reduced plant vigor, exposure of fruit to sunburn, reduced yield, as well as spots and rots on fruit. Yield losses in severely affected crops under conducive environmental conditions can be 100\% (Ritchie 2007; Zitter 1985). The causal agent of bacterial spot has been reclassified several times and was separated into four distinct species: Xanthomonas euvesicatoria, $X$. vesicatoria, $X$. perforans, and X. gardneri (Jones et al. 2004).

Geographic distribution of the four species has changed dramatically over the years (Potnis et al. 2015). X. euvesicatoria and $X$. vesicatoria have been dominant species on pepper. There have been increasing numbers of outbreaks caused by the emerging species $X$. gardneri and $X$. perforans on tomato and/or pepper, such as the 2010 outbreak in the Midwest, and identification of novel

${ }^{\dagger}$ Corresponding author: W. P. Wechter; Pat.Wechter@ars.usda.gov

Funding: This research used resources provided by the U.S. Department of Agriculture Agricultural Research Service (USDA ARS) SCINet project (ARS project number 0500-00093-001-00-D) and was funded by USDA ARS project number 6080-22000-028-00-D.

N. Potnis and S. E. Branham contributed equally to this work.

*The $\boldsymbol{e}$-Xtra logo stands for "electronic extra" and indicates that three supplementary tables are published online.

The author(s) declare no conflict of interest.

This article is in the public domain and not copyrightable. It may be freely reprinted with customary crediting of the source. The American Phytopathological Society, 2019. lineages of $X$. perforans with added ability to cause disease on pepper (Ma et al. 2011; Schwartz et al. 2015). A survey conducted between 2010 and 2013 on tomato and pepper production areas in Ohio and Michigan indicated that $X$. euvesicatoria was the dominant species on pepper, with $X$. gardneri being present in $23 \%$ of the samples. Thus, the ability of $X$. gardneri to infect both tomato and pepper and its predominance in the recent outbreaks in the Midwest are of concern in both tomato and pepper production (Ma 2015). X. gardneri is noted for its aggressiveness, causing large star-shaped lesions on the fruit. Such fruits with large lesions are unacceptable in fresh as well as processed markets (Miller 2012).

The increasing number of bacterial spot outbreaks caused by emerging variants of xanthomonads highlights the importance of finding practical, immediate solutions for growers. Current strategies rely heavily on bactericides including copper. However, these compounds are ineffective under strong disease pressure and have a negative impact on the environment, so we must find sustainable alternatives. Thus, host resistance will be a critical component of disease management strategies. Resistance breeding programs have been successful in developing commercial pepper lines with hypersensitive and quantitative resistance (Stall et al. 2009). However, durability of resistance has been elusive as a result of the changing geographic distribution of the pathogen and emergence of new pathogenic variants.

Six dominant resistance $(\mathrm{R})$ genes have been identified in pepper: namely $B s 1, B s 2, B s 3, B s 4 C, B s 7$, and $B s T$ (Stall et al. 2009). Avirulence genes corresponding to these resistance genes have been identified. As plant resistance was identified in pepper genotypes, pathogenic races were identified based on differential reactions on resistant genotypes. The dominant resistance genes, Bsl (from C. annuum plant introduction [PI] 163192), Bs2 (from C. chacoense PI 260435), and Bs3 (from C. annuum PI 271322), which confer resistance to certain races of $X$. euvesicatoria, have been introgressed into commercial bell pepper cultivars. Race shifts in bacterial spot xanthomonads in response to resistance gene deployments have been common. The avirulence gene avrBsl, which interacts with resistance gene $B s l$ in pepper, was linked with copper resistance on a large self-transmissible plasmid. avrBsl was 
found to be inactivated by insertion sequence IS476, leading to the emergence of spontaneous mutants resulting in race shift. The bacterial gene $a v r B s 2$ that interacts with $B s 2$ in pepper has been considered an important virulence factor that when mutated would render the bacterium less aggressive (Kearney and Staskawicz 1990). However, strains were isolated with non-synonymous point mutations in avrBs 2 that resulted in AvrBs2 not being recognized by Bs2, but maintaining virulence (Gassman et al. 2000). The avirulence gene $a v r B s 3$, which elicits a hypersensitive response in pepper with the $B s 3$ resistance gene, is found on a plasmid. Loss of avrBs 3 plasmid from race 1 strains, resulting in race shift to race 3 , was reported by Kousik and Ritchie (1996) in field plots of pepper possessing the $B s 3$ gene. Bacterial strains exhibiting virulence on cultivars carrying one or more dominant resistance genes have been isolated (Bouzar et al. 1994; Kousik and Ritchie 1998). Currently, 11 pathogenic races of Xanthomonas on pepper have been identified. Although resistance gene pyramiding has offered advantages in certain combinations, none of these combinations have been successful in controlling disease without the need for additional control measures.

In addition to hypersensitive type resistance, quantitative resistance has also been identified. The level of quantitative resistance identified in pepper accessions with two to three recessive $\mathrm{R}$ genes varies in response to different species of bacterial spot pathogen. Breeding efforts have enabled transfer of quantitative resistance to commercial varieties in an additive fashion governed by $b s 5$ and $b s 6$. Although PIs containing these additive recessive genes exhibit a higher level of resistance toward $X$. euvesicatoria, $X$. gardneri strains caused an aggressive reaction on plants containing individual as well as combined recessive resistance genes (Stall et al. 2009).

Bacterial spot can be caused by four distinct species, complicating a resistance-based management strategy. Identifying resistance genes effective against a constantly changing population of the four species, as well as a changing geographic distribution, remains challenging. Introgression of resistance genes with different modes of gene action can provide a durable solution to this continuous host-pathogen arms race. Failure of commercial pepper varieties with recessive genes to be effective against $X$. gardneri, as well as increasing outbreaks caused by $X$. gardneri around the world, warrants the identification of novel sources of resistance in pepper against emerging species, including $X$. gardneri, and the incorporation of these novel resistances in breeding programs. Studies have utilized the power of correlating high-density single nucleotide polymorphism (SNP) markers with phenotypic traits through genome-wide association studies (GWAS). GWAS of various plant-pathogen systems have facilitated the mapping of novel alleles associated with disease resistance (Dilla-Ermita et al. 2017; Jia et al. 2012; Tung et al. 2010; Wang et al. 2012, 2014; Zhang et al. 2016; Zhu et al. 2008).

The goal of the current project was to find novel sources of resistance to $X$. gardneri in pepper and to identify potential candidate genes involved in bacterial spot disease resistance. We screened a diverse USDA panel of pepper germplasm for resistance to $X$. gardneri and found highly resistant germplasm. In addition, using high-throughput sequencing technologies to facilitate GWAS, we identified novel resistance quantitative trait loci (QTLs) associated with bacterial spot of pepper.

\section{MATERIALS AND METHODS}

Plant material and growth conditions. The USDA pepper PIs (287 accessions) were obtained from the U.S. plant germplasm repository at the Plant Genetic Resources Conservation Unit in Griffin, Georgia. These 287 PIs included 158 PIs belonging to C. annuum, nine PIs belonging to $C$. annuum var. glabriusculum, five PIs belonging to $C$. baccatum, 35 PIs belonging to $C$. baccatum var. pendulum, one PI belonging to $C$. baccatum var. praetermissum, one PI belonging to $C$. baccatum var. umbilicatum, one PI belonging to $C$. chacoense, 44 PIs belonging to $C$. chinense, 24 PIs belonging to $C$. frutescens, one PI belonging to $C$. galapagoense, four PIs of C. pubescens, and four belonging to Capsicum spp. The designation of the species of Capsicum mentioned above and in the figures is based on the metadata obtained from the U.S. plant germplasm repository. Twelve individuals from each PI accession were grown in Metro-Mix 360 (Sun Gro Horticulture, Agawam, MA) in 50-cell trays (PRO050R5; Myers Industries Lawn and Garden Group, Middlefield, $\mathrm{OH}$ ) until the cotyledon stage, at which time the plants were transferred into plastic $10 \times 10 \times 10$-cm pots and fertilized with Osmocote (Everris NA Inc., Dublin, OH). Plants were grown in two replicates of six plants each in a greenhouse (average temperature of $25^{\circ} \mathrm{C}$, ranging between 18 and $38^{\circ} \mathrm{C}$ ) for 4 to 5 weeks prior to inoculation.

$X$. gardneri inoculum preparation. A highly virulent strain of $X$. gardneri (USVLXG1), isolated from infected tomatoes from an outbreak of the disease in Ohio, was streaked to single colonies on nutrient agar (NA) plates. USVLXG1 was maintained as a $15 \%$ glycerol stock at $-80^{\circ} \mathrm{C}$ in the Wechter Laboratory at the U.S. Vegetable Laboratory (USDA Agricultural Research Service, Charleston, SC). After 2 days, single colony isolates were then streaked onto fresh NA plates and grown at $27^{\circ} \mathrm{C}$ in an incubator for $48 \mathrm{~h}$. Cells were scraped from the plates and resuspended in sterile tap water to an optical density of 0.3 at $600 \mathrm{~nm}$, which equates to $\sim 1 \times 10^{8} \mathrm{CFU} \mathrm{m}{ }^{-1}$. This stock then was diluted again to a final concentration of $1 \times 10^{6} \mathrm{CFU} \mathrm{ml}{ }^{-1}$ with sterile tap water, then amended with $0.04 \%$ of the wetting agent Silwet L-77 (Helena Chemical Co., Collierville, TN). Inoculated plants were maintained in the greenhouse using standard practices for the remainder of the experiment.

$X$. gardneri inoculation and host resistance evaluation. The entire foliar portion of each plant was inverted and submerged in the inoculum for $30 \mathrm{~s}$. Plants were then randomized and returned to the greenhouse bench. The cultivars Early California Wonder (susceptible), 56R (tolerant), and 30R (resistant) were included in each test as controls. Two-hundred eighty-seven accessions were tested along with pepper genotypes with known reactions to $X$. gardneri, which are commonly used as recipient parents for generating genetic populations and include the cultivars Early Calwonder (ECW; susceptible to $X g$ ), ECW-20R (containing resistance alleles for the $B s 2$ gene), ECW-30R (containing resistance alleles for the $B s 2$ gene), and ECW-56R (containing recessive resistance alleles for $b s 5$ and $b s 6$ ). Disease severity was evaluated 14 days postinoculation by ratings based on the percentage of area covered by bacterial spot lesions on three middle leaves of each plant. The disease severity scale was as follows: 0 , no lesions observed; 1 , trace but less than $1 \%$ leaf area diseased; 2,1 to $10 \%$ of leaf area diseased; 3,11 to $20 \%$ of leaf area diseased; 4,21 to $35 \%$ of leaf area diseased; 5, 36 to $50 \%$ of leaf area diseased; 6,51 to $65 \%$ of leaf area diseased; 7,66 to $80 \%$ of leaf area diseased; 8,81 to $99 \%$ of leaf area diseased; and 9, $100 \%$ of leaf area diseased/if defoliated (Kousik and Ritchie 1998; Kousik et al. 1996). We also used the percentage of defoliation for each plant as an indicative trait for the level of disease resistance because this is a classic symptom observed with $X$. gardneri on susceptible pepper. Based on the disease ratings, the PIs were classified into four phenotypic categories: highly resistant (disease ratings of 0 to 2 ), moderately resistant (disease ratings of $>2$ to 4 ), moderately susceptible (disease ratings of $>4$ to 6 ), and highly susceptible (disease ratings of $>6$ to 9 ).

Statistical analyses. Adjusted means for defoliation and disease severity were used as the phenotypic traits for GWAS analysis. Adjusted genotypic means for each C. annuum PI, using the checks to correct for environmental variation between incomplete blocks, were calculated with the 'easyanova' package (Arnhold 2013) in R software version 3.2.5 (R Core Team 2016) with the design parameter set to augmented incomplete block. The same checks (30R, 56R, and ECW) were used in every incomplete 
block to reduce error by controlling for blocking effect and experimental error variance with an augmented incomplete block design (Federer and Raghavarao 1975). Variance components, for estimation of broad-sense heritability, were determined with a restricted maximum likelihood mixed model using ASReml-R version 3.0 (Gilmour et al. 2009) in $R$ version 3.2.5. The model for both defoliation and disease severity rating included the following: accession (random), check (fixed), the interaction between check and block (fixed), block (random), replicate nested in block (random), and plant nested in accession (random).

Genomic DNA extraction and polymerase chain reaction screening. Genomic DNA was extracted from young leaf tissue of a single representative plant per accession. DNA was extracted from $100 \mathrm{mg}$ of leaf tissue using the DNeasy Plant Mini kit (Qiagen, Germantown, MD). The tissues were homogenized in 1.5-ml screwcap microcentrifuge tubes in a solution containing $400 \mu \mathrm{l}$ of buffer AP1 and $4 \mu 1$ of RNase A using a FastPrep FP120 homogenizer on setting $4 \mathrm{~m} / \mathrm{s}$ for $20 \mathrm{~s}$ (Thermo Fisher Scientific, Waltham, MA) with a quarter-inch ceramic bead (MP Biomedicals, Santa Ana, CA) in each microcentrifuge tube. The DNeasy protocol was then followed to completion. PIs rated as highly resistant, moderately resistant, or moderately susceptible (ratings 0 to 6 ) were subjected to polymerase chain reaction (PCR) screening for the presence of known resistance alleles of $B s 2$ and $B s 3$ (using primers and settings optimized by Romer et al. 2010 and Troung et al. 2011).

Sequencing and SNP calling. We followed a selective genotyping approach (Darvasi and Soller 1992) to choose a subset of 187 PIs from the 287 phenotyped accessions for genotyping by sequencing (GBS). Accessions from all four phenotypic categories were chosen, including all of the highly resistant accessions and more than half of the accessions from each of the remaining categories (moderately resistant, moderately susceptible, and highly susceptible). In addition, we also included control lines including ECW and near-isogenic lines derived from ECW containing known resistance alleles for Bs2 (20R), Bs3 (30R), and Bs5/6 (56R) as well as CM334 (for which the complete genome is available) for GBS. Purified DNA was then quantified using the Quant-iT dsDNA assay kit, broad range (Thermo Fisher Scientific), on a Qubit Fluorometer (Thermo Fisher Scientific). DNA samples were sent to two facilities for library preparation and sequencing: one plate (95 samples) was sent to the Genomic Diversity Facility at Cornell University (Ithaca, NY) and the second plate was processed by the DNA Sequencing Facility at the University of WisconsinMadison (Madison, WI). Libraries (96-plex) were prepared by digestion of genomic DNA with ApeKI (Elshire et al. 2011) and were sequenced as 100-bp, single-end reads on an Illumina HiSeq 2000/2500 system. Processing of raw reads and SNP calling was completed with the GBSv2 pipeline of TASSEL 5.2.30 (Bradbury et al. 2007; Glaubitz et al. 2014) using default parameters. Unique sequence tags were aligned to the $C$. апnиum hot pepper reference genome (Kim et al. 2014) with the Burrows-Wheeler aligner version 0.5.9 (Li and Durbin 2009, 2010). Likely genotyping errors were filtered with VCFtools version 0.1.15 (Danecek et al. 2011), for each grouping of PIs described below, by removing SNPs with a minor allele frequency (MAF) of less than 0.01 and/or $>90 \%$ missing data.

Genotypes for GWAS. Missing allele calls for SNPs polymorphic in the C. annuum PIs (postinitial filtering) were imputed in BEAGLE version 4.1 (Browning and Browning 2007, 2016) without a reference panel and using default settings with 10 burnin iterations and 15 phasing iterations. High-quality SNPs with a MAF $>0.05$ were used for GWAS.

Population structure. Genetic distances were visualized for all peppers in the GWAS panel $(n=187)$ using principal coordinates analysis (PCoA). An additional PCoA of accessions excluding C. baccatum PIs was generated to provide better separation of the clusters corresponding to the more closely related species in the genus ( $C$. annuum, $C$. chinense, and $C$. frutescens). Several PIs were clearly misidentified as the PIs clustered tightly by species. For all C. annuum-specific analyses (PCoA, STRUCTURE, heritability, and GWAS), we used all PIs that fell within the $C$. annuum cluster of this PCoA. The relationship between genetic distance and country of collection of the PI was examined through a PCoA of all accessions that formed the $C$. annuum cluster. PCoAs were calculated in TASSEL 5.2.35 (Bradbury et al. 2007) using genetic distance matrices generated from polymorphic markers specific to each data set. To more closely examine the fine-scale population stratification of $C$. annuum PIs, they were clustered into populations with the program STRUCTURE version 2.3.4 using the admixture model with correlated allele frequencies (Falush et al. 2003, 2007; Hubisz et al. 2009; Pritchard et al. 2000). SNPs polymorphic within the $C$. annuum PIs were filtered by linkage disequilibrium (LD) to meet the assumptions of unlinked SNPs for population structure analyses. LD pruning was completed in SVS version 8.7.0 (Golden Helix Inc., Bozeman, MT; http://www.goldenhelix.com/) using default settings.

Population numbers $(\mathrm{K})$ of 1 to 9 were run 10 times each with 35,000 burn-in iterations and 35,000 Markov chain Monte Carlo repetitions. Summaries and figures of the STRUCTURE results were generated with the analysis pipeline CLUMPAK version 1.1 (Kopelman et al. 2015), which includes the software packages CLUMPP version 1.1 (Jakobsson and Rosenberg 2007), MCL version 14-137 (Enright et al. 2002; Van Dongen 2000), and DISTRUCT version 1.1 (Rosenberg 2004). Values for multiple runs of each $\mathrm{K}$ value were compared using 2,000 iterations of the largeKGreedy algorithm of CLUMPP and distinct solutions for each K separated with MCL. The optimal K value was determined using the delta-K method described in Evanno et al. (2005). Membership coefficients for each $C$. annuum PI were graphically displayed by geographic region using DISTRUCT.

GWAS. Mixed linear model (MLM) analysis of the adjusted means of defoliation and disease severity in the $C$. annuum accessions ( $n=107$; owing to a lack of germ for one PI) was performed with SNP and Variation Suite version 8.7.0 software (Golden Helix Inc.). An additional GWAS using a binary descriptor of the sequencing plate was done to search for sequencing bias introduced by the different laboratories that performed the sequencing. SNPs significantly associated with the sequencing plate were removed from all analyses. Associations were detected with a variance component approach utilizing EMMAX (Kang et al. 2010) and P3D (Zhang et al. 2010). Population structure and relatedness were controlled by inclusion of an identity-by-state matrix and five principal coordinates in the MLM. A Bonferroni correction was applied to the GWAS $P$ values to determine a genome-wide significance threshold of 0.05 . Manhattan and quantile-quantile (QQ) plots of association values were generated with the qqman package in $\mathrm{R}$ (Turner 2014). The pepper reference genome annotation (version 1.55) of Mexican landrace CM334 (Kim et al. 2014) was used to generate a list of candidate genes within $\pm 150 \mathrm{~kb}$ of the significant SNP. The distance of $150 \mathrm{~kb}$ was chosen to capture the most likely genes in LD with our significant SNPs, as previous genome-wide estimates of LD in C. annuum using GBS data were $139 \mathrm{~kb}$ (Nimmakayala et al. 2016) and $100 \mathrm{~kb}$ (Taranto et al. 2016).

Data archiving. All phenotypic and genotypic data associated with this research are available in Supplementary Tables S1, S2, and $\mathrm{S} 3$.

\section{RESULTS}

Bacterial spot disease screening in pepper accessions. A highly virulent strain of $X$. gardneri (USVLXG1) was selected to screen 287 pepper genotypes belonging to C. annuum, C. baccatum, C. chacoense, $C$. chinense, $C$. frutescens, $C$. galapagoense, $C$. pubescens, and Capsicum spp. Phenotyping of the control lines, ECW (highly susceptible), and ECW-56R (moderately susceptible) conformed to 
the expected disease reactions. ECW-20R and ECW-30R carried $B s 2$ and $B s 3$ resistance alleles, respectively. Both lines were moderately resistant based on disease severity ratings of 3.9 and 3.7, respectively. This could be attributed to low levels of observed segregation in our replicated experiments. We observed a wide range of disease resistance among the PIs, with $40 \%$ of the genotypes exhibiting high susceptibility (disease ratings of $>6$ to 9 ), $33.8 \%$ genotypes showing moderate susceptibility (disease ratings of $>4$ to 6 ), $21 \%$ exhibiting moderate resistance (disease ratings of $>2$ to 4 ), and $5.2 \%$ exhibiting high resistance (disease ratings of 0 to 2) (Fig. 1). It is important to note here that these categories were based on the average disease severity ratings and that $29.3 \%$ of the accessions were segregating. Significant differences $(P<0.0001)$ were observed among the 287 PIs based on both disease severity rating as well as defoliation rating according to the KruskalWallis test. Among the different Capsicum spp. screened here, $C$. baccatum contained the highest proportion of resistant PIs, with $\sim 10 \%$ of the phenotyped $C$. baccatum var. pendulum PIs $(n=35)$ being highly resistant and $60 \%$ of the phenotyped $C$. baccatum PIs $(n=5)$ being moderately resistant based on disease severity (Fig. 1). The $C$. chacoense PI 260435, the original source of the resistance allele of the Bs2 gene (Tai et al. 1999), displayed a high level of resistance against $X$. gardneri in our phenotyping screen. $C$. baccatum and $C$. chacoense genotypes also displayed lower percentages of defoliation. Fifty-five percent of the PIs in our screen belonged to $C$. annuum, $20 \%$ of which were classified as highly or moderately resistant (Fig. 1). The original source of the Bs3

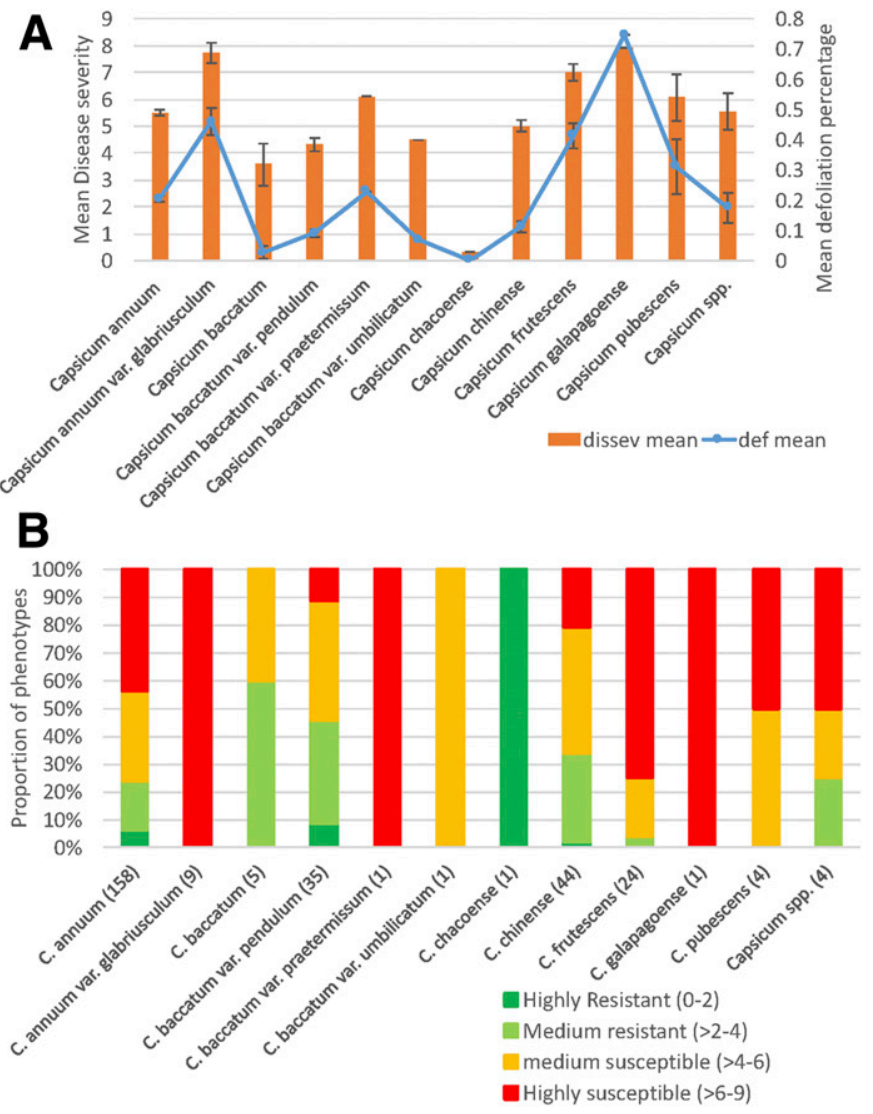

Fig. 1. Phenotyping of the U.S. Department of Agriculture collection of 287 Capsicum accessions inoculated with a representative strain of Xanthomonas gardneri (USVLXG1). A, Bar graph of mean disease severity (dissev) and mean defoliation rating (def) across the collection after artificial inoculation with USVLXG1. The error bars indicate standard error. B, Proportion of accessions displaying each category of reaction after inoculation with USVLXG1: highly resistant (disease ratings of 0 to 2), moderately resistant ( $>2$ to 4 ), moderately susceptible ( $>4$ to 6 ), and highly susceptible ( $>6$ to 9 ). resistance allele, PI 271322 (C. annuum), showed moderate resistance with disease severity ratings ranging from $>2$ to 4 and $1.6 \%$ defoliation. We further screened highly resistant, moderately resistant, and moderately susceptible PIs $(n=172)$ for the presence of known bacterial spot disease resistance alleles for $B s 2$ and $B s 3$, using primers developed by Troung et al. (2011) and Romer et al. (2010), respectively. Of these, 13 PIs (10 PIs of $C$. annuum, two of $C$. frutescens, and one of $C$. chinense) contained $B s 3$ resistance alleles and three PIs (two belonging to $C$. pubescens and one belonging to $C$. chacoense) contained $B s 2$ resistance alleles. The average disease severity rating for the PIs with $B s 3$ resistance alleles was 3.65, although six of the PIs were segregating for resistance. The average disease severity for the PIs with $B s 2$ resistance alleles was 3.70 , with two of three PIs segregating for disease resistance.

Mixed model analysis of resistance traits in the GWAS panel ( $n=107$ C. annuum PIs) revealed differences in the sources of variation contributing to the overall variance observed in defoliation and disease severity (Tables 1 and 2). Broad-sense heritability of disease severity $\left(\mathrm{H}^{2}=0.62\right)$ was much higher than that of defoliation $\left(\mathrm{H}^{2}=0.37\right)$. The main environmental component that explained the decrease in genetic contribution for defoliation was the high proportion of the overall phenotypic variation attributed to blocks (36.9\%). Even though the resistance traits were rated on the same plants at the same time, block only explained $3.9 \%$ of the variation in disease severity.

Genotyping. We selected 187 PIs for sequencing that represented resistant, moderately resistant, and susceptible phenotypes, which included three PIs with $B s 3$ resistance alleles (PI 271322, PI653619, and Grif 9271) along with the control lines including ECW and near-isogenic lines derived from ECW containing known resistance alleles for $B s 2$ (20R), Bs3 (30R), and $B s 5 / 6$ (56R). Sequencing produced $>438$ million high-quality barcoded reads, which grouped into 1,195,192 unique tags and generated 388,971 SNPs. Per sample mean read depth ranged from 4.9 to 30.4 across the pepper data set, with the exception of a single poorly sequenced (mean depth of 0.38 ) $C$. frutescens accession (PI 14015). The pepper genotypes were used only for the purpose of verifying the species identity of the accessions; therefore, this sample was retained and was not reclassified. Mean read depth across the Capsicum PIs was 15.8 with a standard deviation of 5.4. The mean read depth per sample for the $C$. annuum data set ranged from 9.5 to 30.4 , with an overall mean of 18.7 and a standard deviation of 4.8. Filtering of sequencing errors (MAF $<0.01$ and/or $>90 \%$ missing calls) within each data set (all genotyped peppers,

TABLE 1. Variance components of defoliation in the U.S. Department of Agriculture Capsicum annuum plant introduction collection $(n=107)$

\begin{tabular}{lcccc}
\hline Variance component & Variance & $\%_{\mathrm{V}_{\mathrm{P}}}{ }^{\mathrm{a}}$ & Standard error & $P$ value $^{\mathrm{b}}$ \\
\hline Accession (A) & $3.1 \times 10^{-2}$ & 37.4 & $4.7 \times 10^{-3}$ & 0 \\
Block (B) & $3.1 \times 10^{-2}$ & 36.9 & $2.3 \times 10^{-2}$ & $5.9 \times 10^{-4}$ \\
Replicate within B & $2.1 \times 10^{-9}$ & $2.6 \times 10^{-6}$ & $9.2 \times 10^{-11}$ & 1 \\
Plant within A & $2.6 \times 10^{-9}$ & $3.1 \times 10^{-6}$ & $1.1 \times 10^{-10}$ & 1 \\
Residual & $2.1 \times 10^{-2}$ & 25.6 & $9.1 \times 10^{-4}$ & $\mathrm{NA}$ \\
\hline
\end{tabular}

a Percentage of the phenotypic variation explained by the variance component. b $\mathrm{NA}=$ not applicable.

TABLE 2. Variance components of disease severity in the U.S. Department of Agriculture Capsicum annuum plant introduction collection $(n=107)$

\begin{tabular}{llrcc}
\hline Variance component & Variance & $\% \mathrm{~V}_{\mathrm{P}}^{\mathrm{a}}$ & Standard error & $P$ value $^{\mathrm{b}}$ \\
\hline Accession (A) & 3.7 & 62.2 & 0.54 & 0 \\
Block (B) & 0.23 & 3.9 & 0.40 & 0.44 \\
Replicate within B & 0.065 & 1.1 & 0.045 & $9.9 \times 10^{-7}$ \\
Plant within A & 0.36 & 6.1 & 0.041 & 0 \\
Residual & 1.6 & 26.7 & 0.23 & $\mathrm{NA}$ \\
\hline
\end{tabular}

a Percentage of the phenotypic variation explained by the variance component. b $\mathrm{NA}=$ not applicable. 
$n=187$; PIs excluding $C$. baccatum, $n=161$; and only $C$. annuum, $n=108$, as determined by genetic distance) reduced the number of markers to 367,549 SNPs, 293,160 SNPs, and 92,281 SNPs, respectively. After removal of SNPs with significant plate ascertainment bias (65 SNPs), a final set of 90,794 high-quality SNPs with a MAF > 0.05 was used for all association tests. Imputation of the $C$. annuum genotypes with BEAGLE reduced the missing data to $0 \%$. Mean SNP spacing varied from 25 to $40 \mathrm{~kb}$ per chromosome, while the maximum distance ranged from 1.1 to 2.7 $\mathrm{Mb}$. Additional filtering by LD to remove linked SNPs reduced the data set to 34,648 SNPs for C. annuum PIs, which were used for STRUCTURE analysis.
Genetic diversity and population structure. We visualized genetic diversity among 187 accessions of pepper, representing four species of Capsicum (namely C. annuum, C. baccatum, C. chinense, and $C$. frutescens) and undefined Capsicum species, using PCoA (Fig. 2A). The first principal coordinate explained $55.5 \%$ of the genetic variation and separated the PIs into three groups. C. baccatum was genetically distant from the other species. C. chinense and C. frutescens, while readily distinguishable from one another, formed a combined cluster. To improve the separation of the accessions of these two species, a separate PCoA was generated, excluding the distant C. baccatum (Fig. 2B). Seventynine percent of the genetic variation was explained by the first
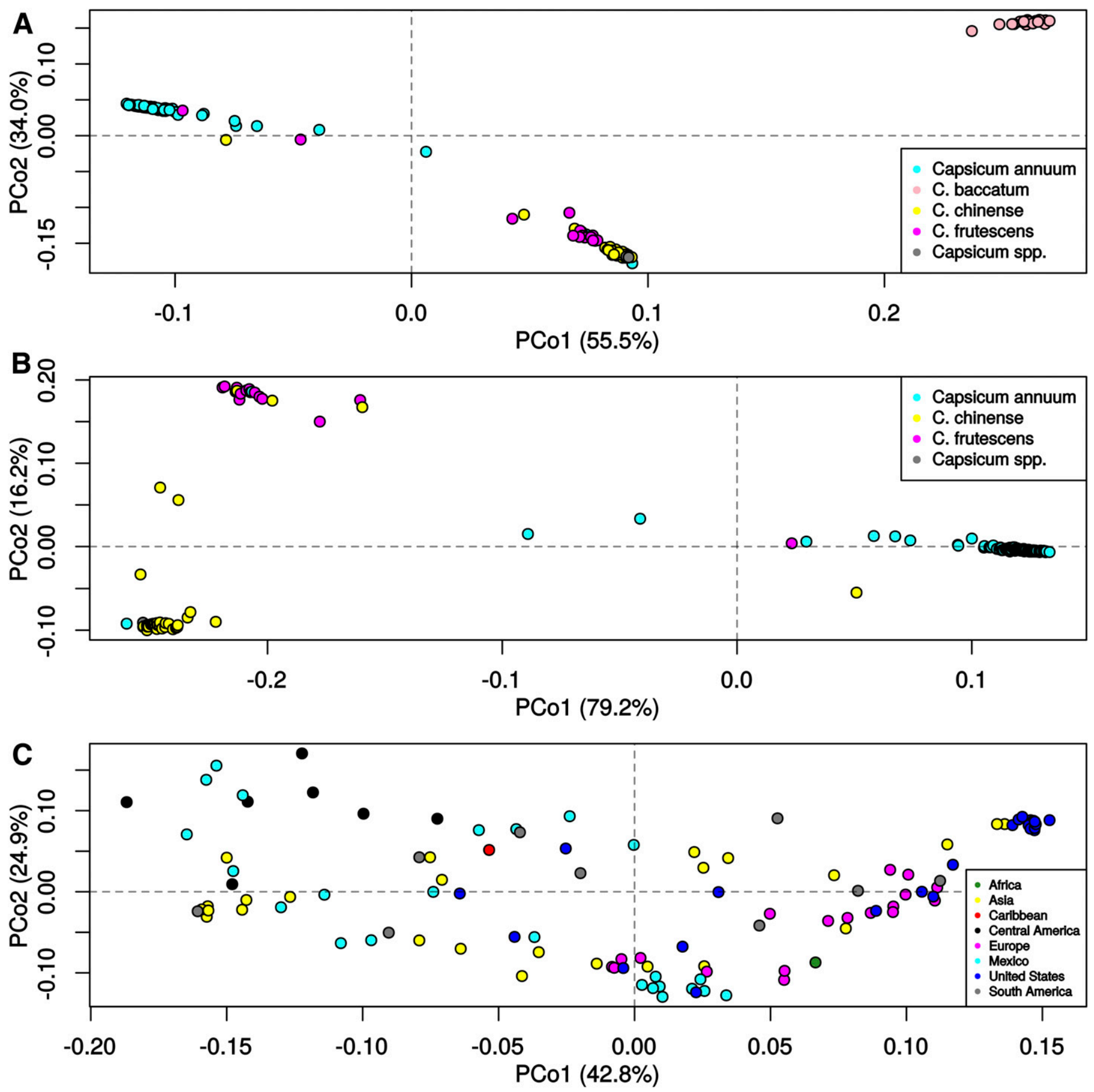

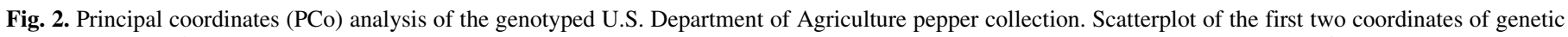

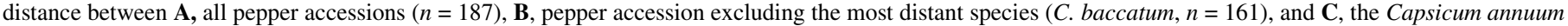
subset $(n=108)$ of the collection. 
principal coordinate, which separated C. annuum from $C$. frutescens and $C$. chinense. The distance between $C$. frutescens and $C$. chinense was responsible for the second coordinate $(16.2 \%$ of the genetic variation), showing that these species are the most closely related of the set. With the improved separation, after exclusion of C. baccatum, it became clear that nine individuals were likely misidentified in the Germplasm Resources Information Network (GRIN), as they tightly cluster with different species groups than their current GRIN descriptors. The two PIs that were originally described as unidentified Capsicum spp. both cluster with $C$. chinense.

Population structure among the $C$. annuum PIs was examined with PCoA and STRUCTURE analysis. The diverse PIs were spread widely across the first two principal coordinates of the PCoA plot, with a few noticeable geographic trends (Fig. 2C). Several U.S. cultivars formed a tight cluster in the upper-right quadrant, indicating low genetic diversity among them. The European and Central American PIs were distant from one another, as they fell in the extremes of the plot. The PIs collected from Asia have wide genetic diversity, as they were spread across all four quadrants. STRUCTURE analysis separated the $C$. апnиum PIs into two

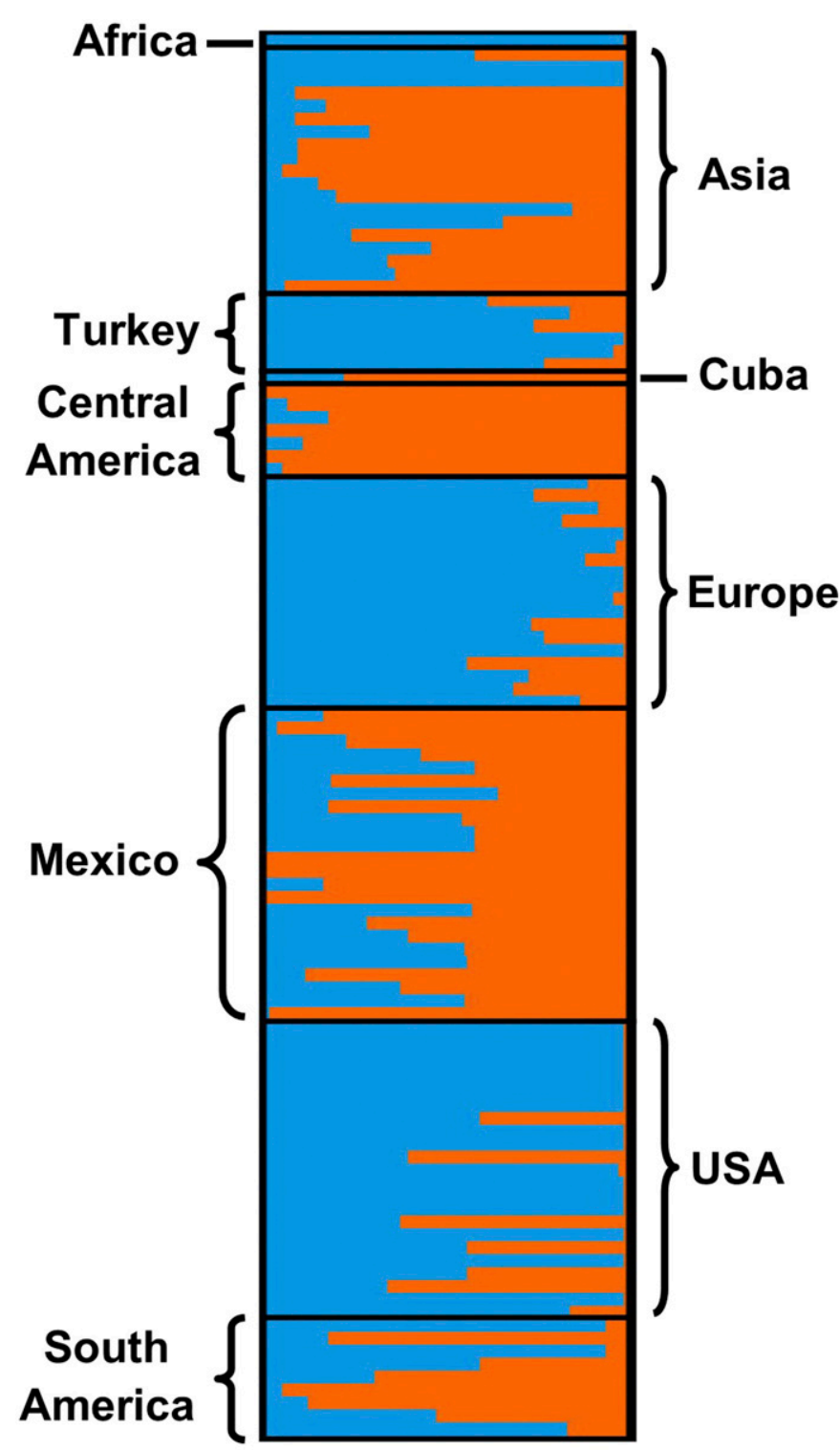

Fig. 3. DISTRUCT plot of Capsicum annuum STRUCTURE results using $\mathrm{K}=$ 2 as determined by the Evanno delta-K method. Accessions are displayed as horizontal bars and black lines separate the accessions into a priori groupings based on geographic origin. The horizontal bars are shaded according to their proportional membership coefficient for each cluster (genetic grouping). clusters (Fig. 3). Most individuals were admixed with membership coefficients in both clusters $(71 \%)$, while fewer individuals were derived from only the dark (22\%) or light clusters (7\%). Accessions from the United States, Europe, and Turkey had higher representation from the dark cluster, Central America from the light cluster, and Asia, Mexico, and South America were admixed.

Genome-wide association analysis. We used GWAS to identify SNPs associated with resistance to $X$. gardneri in $C$. annuum $(n=107)$. The GWAS models chosen used both principal components and a kinship matrix to correct for population structure and relatedness. This model was appropriate for disease severity (Fig. 4B), but a QQ plot of the observed versus expected $P$ values for defoliation showed a slight inflation of the observed value (Fig. 4A), indicating a higher likelihood of residual false-positive associations. Therefore, the highly conservative Bonferroni correction was used to control for false-positive associations. We identified 20 significant SNPs associated with defoliation, which collocated within $150 \mathrm{~kb}$ of 92 unique genes on chromosomes 1, 2, 3, 8, and 10 (Fig. 5A). There were no significant SNPs associated with disease severity (Fig. 5B).

\section{DISCUSSION}

Screening of the USDA pepper collection for resistance to $X$. gardneri revealed several highly resistant genotypes. Use of a dip-inoculation technique for germplasm screening allowed identification of non-hypersensitive response-type resistance sources that are often missed using typical infiltration inoculation techniques. Dip inoculation also enabled evaluation of defoliation. Bacterial spot xanthomonads, especially $X$. gardneri, cause severe defoliation in highly susceptible varieties as a part of their pathogenesis. Future studies of $X$. gardneri resistance, however, should concentrate on disease severity because it is a better indicator of a resistant genotype owing to much higher heritability than that of defoliation. Despite the high heritability of disease severity, no QTLs were significantly associated with this trait. The large genome size of $C$. annuum combined with the low coverage of
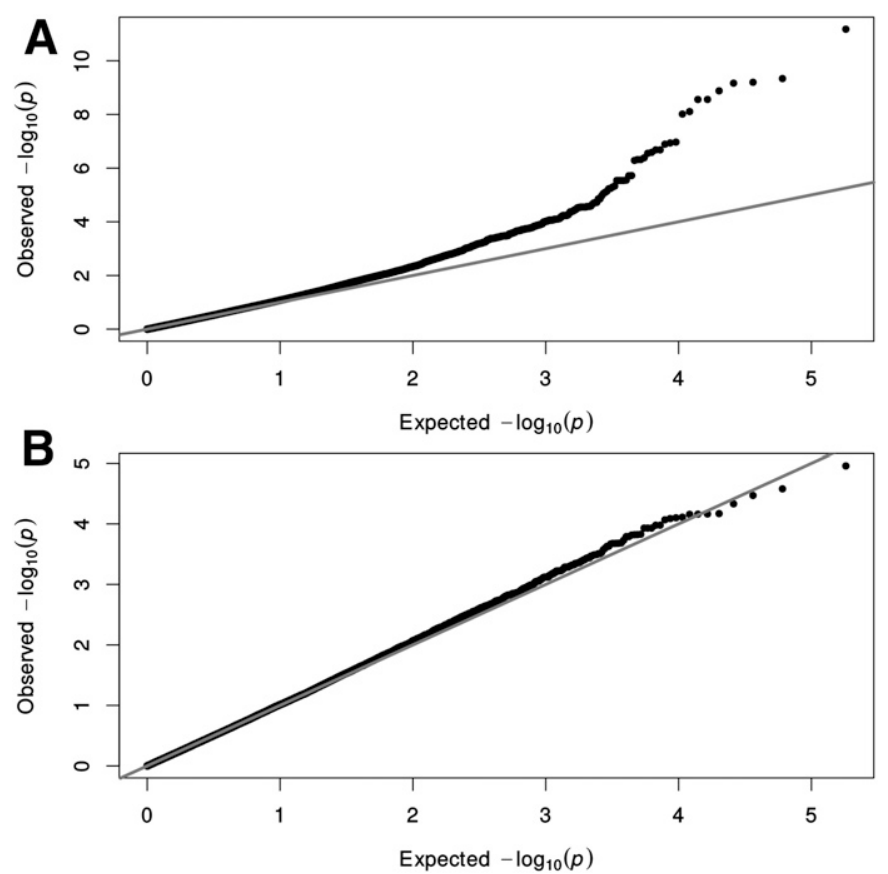

Fig. 4. Quantile-quantile plots of the observed distribution of $P$ values plotted against the distribution expected under the null hypothesis. $P$ values were obtained from genome-wide association analysis of $\mathbf{A}$, defoliation and $\mathbf{B}$, disease severity. 
GBS led to little to no SNP coverage in some areas of the genome (up to $2.7 \mathrm{Mb}$ ). It is likely that lack of coverage caused falsenegative associations in the GWAS of disease severity. GWAS of defoliation revealed significant QTLs associated with resistance to bacterial spot disease caused by $X$. gardneri. Candidate genes based on defoliation encoded products that have been previously shown to function in disease resistance against bacterial, fungal, and viral diseases as well as in hormone signaling and in regulating susceptibility. Here we discuss significant QTLs that collocated with candidate genes whose homologs have been identified in other crops to be involved in resistance against pathogens.

Plants have evolved programmed cell death (PCD) to limit pathogen invasion and restrict pathogen spread. We identified several SNPs associated with defoliation that were in close proximity to or were within PCD-related genes, encoding caspases (CA03g14020), the tBRCA2 homolog (CA02g06790), the ubiquitin protein ligase (CA01g19270), and the RING-H2 finger protein coding gene (CA01g19300). The RING-H2 finger protein (belonging to the RING-UBox superfamily) coding gene (CA01g19300) contained three SNPs associated with defoliation. Caspases have been implicated in innate immune response in plants as regulators of cell death. A BRCA2 homolog in Arabidopsis species was involved in systemic acquired resistance by transcriptional regulation of pathogenesis-related genes through interaction with the strandexchange protein RAD51 (Wang et al. 2010). Previous studies have shown the role of ubiquitin protein ligases and RING finger proteins in modulating plant innate immunity, broad-spectrum disease resistance, as well as biotic and abiotic stress response (Joo et al. 2017; Lee et al. 2011; You et al. 2016). XA21-binding protein 3 (XB3), a RING finger containing E3 ubiquitin ligase, was shown to regulate bacterial blight resistance gene encoding receptor kinase XA21 in rice (Huang et al. 2013). Interestingly, ubiquitin protein ligases and RING finger proteins were shown to be targets of pathogen effectors, suggesting their involvement in disease susceptibility (Janjusevic et al. 2006; Park et al. 2012; Üstün and Börnke 2014).
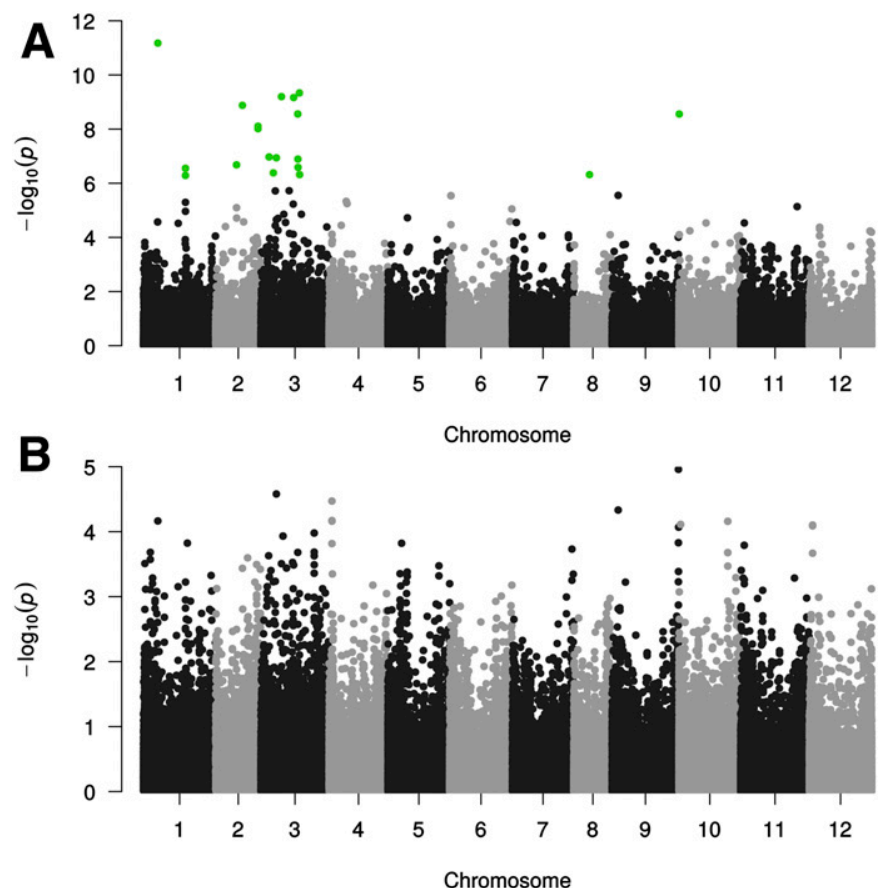

Fig. 5. Genome-wide association mapping results for $\mathbf{A}$, defoliation and $\mathbf{B}$, disease severity across the genotyped U.S. Department of Agriculture Capsicum annuum plant introductions $(n=107)$ after inoculation with Xanthomonas gardneri. The $x$ axis indicates the physical position along each of the 12 pepper chromosomes, which are differentiated by grayscale shading. Single nucleotide polymorphisms exceeding the genome-wide significance level of 0.05 after Bonferroni correction are above $-\log _{10}(\mathrm{p})$ of 6.2 .
The ethylene response factor, ERF5 (CA03g13530), collocated with SNPs associated with defoliation. The role of ethylene response factors in immunity against Xanthomonas species has been investigated in tomato. The Xanthomonas effector, XopD, targets ethylene responsive factor in tomato, which suppresses ethylene production in the host plant, thereby inhibiting ethylenestimulated immunity (Kim et al. 2013).

Although ECW20R, ECW30R, and PIs containing resistant alleles of the $B s 2$ and $B s 3 \mathrm{R}$ genes (based on PCR screening) were included in this study and had moderately resistant disease severity ratings (ranging from $>2$ to 4 ) and relatively low defoliation scores, such resistant varieties were not considered in the highly resistant category because of the stringent cutoff of 0 to 2 . Thus, QTLs responsible for $B s 2 / B s 3$-mediated disease resistance were not identified in this analysis. Screening for $B s 2 / B s 3$ resistance gene sequences in the CM334 genome revealed a $100 \%$ identical homolog on chromosome 2 for the $B s 3$ gene, whereas several homologs annotated as a Bs2 resistance protein with 82 to $89 \%$ identity were on chromosomes 5, 6, 7, 9, and 10. QTLs associated with strong resistance in this study did not collocate (within $\pm 150 \mathrm{~kb}$ ) with the $B s 3$ gene or any of the paralogs of the $B s 2$ gene.

Race shifts in bacterial spot pathogen populations are common (Horvath et al. 2012; Stall et al. 2009) and have been a challenge for pepper breeding programs by decreasing the durability of resistance (Gassmann et al. 2000). Thus, identifying novel sources of resistance against these races is necessary. The $X$. gardneri resistance germplasm and QTLs identified here are of considerable importance for breeders and researchers for introgression into elite pepper lines and gene pyramiding efforts against different species of bacterial spot xanthomonads. The novel sources of resistance identified in this study will serve as a primer for further work in breeding of disease-resistant varieties resilient to changing pathogen population structure.

\section{LITERATURE CITED}

Arnhold, E. 2013. Package in the R environment for analysis of variance and complementary analyses. Braz. J. Vet. Res. Anim. Sci. 50:488-492.

Bouzar, H., Jones, J.B., Stall, R.E., Hodge, N. C., Minsavage, G. V., Benedict, A. A., and Alvarez, A. M. 1994. Physiological, chemical, serological, and pathogenic analyses of a worldwide collection of Xanthomonas campestris pv. vesicatoria strains. Phytopathology 84:663-671.

Bradbury, P. J., Zhang, Z., Kroon, D. E., Casstevens, T. M., Ramdoss, Y., and Buckler, E. S. 2007. TASSEL: Software for association mapping of complex traits in diverse samples. Bioinformatics 23:2633-2635.

Browning, B. L., and Browning, S. R. 2016. Genotype imputation with millions of reference samples. Am. J. Hum. Genet. 98:116-126.

Browning, S. R., and Browning, B. L. 2007. Rapid and accurate haplotype phasing and missing-data inference for whole-genome association studies by use of localized haplotype clustering. Am. J. Hum. Genet. 81:1084-1097.

Danecek, P., Auton, A., Abecasis, G., Albers, C. A., Banks, E., DePristo, M. A, Handsaker, R. E., Lunter, G., Marth, G. T., Sherry, S. T., McVean, G., Durbin, R., and 1000 Genomes Project Analysis Group. 2011. The variant call format and VCFtools. Bioinformatics 27:2156-2158.

Darvasi, A., and Soller, M. 1992. Selective genotyping for determination of linkage between a marker locus and a quantitative trait locus. Theor. Appl. Genet. 85:353-359.

Dilla-Ermita, C. J., Tandayu, E., Juanillas, V. M., Detras, J., Lozada, D. N., Dwiyanti, M. S., Vera Cruz, C., Mbanjo, E., Ardales, E., Diaz, M. G., Mendioro, M., Thomson, M. J., et al. 2017. Genome-wide association analysis tracks bacterial leaf blight resistance loci in rice diverse germplasm. Rice (New York, N.Y.) 10:8.

Elshire, R. J., Glaubitz, J. C., Sun, Q., Poland, J., Kawamoto, K., Buckler, E. S., and Mitchell, S. E. 2011. A robust, simple genotyping-by-sequencing (GBS) approach for high diversity species. PLoS One 6:e19379.

Enright, A. J., Van Dongen, S., and Ouzounis, C. A. 2002. An efficient algorithm for large-scale detection of protein families. Nucleic Acids Res. 30: 1575-1584.

Evanno, G., Regnaut, S., and Goudet, J. 2005. Detecting the number of clusters of individuals using the software STRUCTURE: A simulation study. Mol. Ecol. 14:2611-2620.

Falush, D., Stephens, M., and Pritchard, J. K. 2003. Inference of population structure using multilocus genotype data: Linked loci and correlated allele frequencies. Genetics 164:1567-1587. 
Falush, D., Stephens, M., and Pritchard, J. K. 2007. Inference of population structure using multilocus genotype data: Dominant markers and null alleles. Mol. Ecol. Notes 7:574-578.

Federer, W. T., and Raghavarao, D. 1975. On augmented designs. Biometrics 31:29-35.

Gassmann, W., Dahlbeck, D., Chesnokova, O., Minsavage, G. V., Jones, J. B., and Staskawicz, B. J. 2000. Molecular evolution of virulence in natural field strains of Xanthomonas campestris pv. vesicatoria. J. Bacteriol 182: 7053-7059.

Gilmour, A. R., Gogel, B. J., Cullis, B. R., and Thompson, R. 2009. ASReml User Guide Release 3.0. VSN International Ltd., Hemel Hempstead, UK.

Glaubitz, J. C., Casstevens, T. M., Lu, F., Harriman, J., Elshire, R. J., and Sun, Q., and Buckler, E. S. 2014. TASSEL-GBS: A high capacity genotyping by sequencing analysis pipeline. PLoS One 9:e90346.

Horvath, D. M., Stall, R. E., Jones, J. B., Pauly, M. H., Vallad, G. E., Dahlbeck, D., Staskawicz, B. J., and Scott, J. W. 2012. Transgenic resistance confers effective field level control of bacterial spot disease in tomato. PLOS One. https://doi.org/10.1371/journal.pone.0042036

Huang, X., Liu, X., Chen, X., Snyder, A., and Song, W.-Y. 2013. Members of the XB3 family from diverse plant species induce programmed cell death in Nicotiana benthamiana. PLoS One 8. https://doi.org/10.1371/journal. pone.0063868

Hubisz, M. J., Falush, D., Stephens, M., and Pritchard, J. K. 2009. Inferring weak population structure with the assistance of sample group information. Mol. Ecol. Resour. 9:1322-1332.

Jakobsson, M., and Rosenberg, N. A. 2007. CLUMPP: A cluster matching and permutation program for dealing with label switching and multimodality in analysis of population structure. Bioinformatics 23:1801-1806.

Janjusevic, R., Abramovitch, R. B., Martin, G. B., and Stebbins, C. E. 2006. A bacterial inhibitor of host programmed cell death defenses is an E3 ubiquitin ligase. Science 311:222-226.

Jia, L., Yan, W., Zhu, C., Agrama, H. A., Jackson, A., Yeater, K., Li, X., Huang, B., Hu, B., McClung, A., et al. 2012. Allelic analysis of sheath blight resistance with association mapping in rice. PloS One 7:e32703.

Jones, J. B., Lacy, G. H., Bouzar, H., Stall, R. E., and Schaad, N. W. 2004. Reclassification of the xanthomonads associated with bacterial spot disease of tomato and pepper. Syst. Appl. Microbiol. 27:755-762.

Joo, H., Lim, C. W., Han, S. W., and Lee, S. C. 2017. The pepper RING finger E3 ligase, CaDIR1, regulates the drought stress response via ABA-mediated signaling. Front. Plant Sci. 8:690.

Kang, H. M., Sul, J. H., Service, S. K., Zaitlen, N. A., Kong, S. Y., and Freimer, N. B., Sabatti, C., and Eskin, E. 2010. Variance component model to account for sample structure in genome-wide association studies. Nat. Genet. 42:348-354.

Kearney, B., and Staskawicz, B. J. 1990. Widespread distribution and fitness contribution of Xanthomonas campestris avirulence gene Avrbs2. Nature 346:385-386.

Kim, J. G., Stork, W., and Mudgett, M. B. 2013. Xanthomonas type III effector XopD desumoylates tomato transcription factor SIERF4 to suppress ethylene responses and promote pathogen growth. Cell Host Microbe. 13:143-154.

Kim, S., Park, M., Yeom, S. I., Kim, Y. M., Lee, J. M., and Lee, H. A., Seo, E., Choi, J., Cheong, K., Kim, K. T., Jung, K., Lee, G. W., Oh, S. K., Bae, C., Kim, S. B., Lee, H. Y., Kim, S. Y., Kim, M. S., Kang, B. C., Jo, Y. D., Yang, H. B., Jeong, H. J., Kang, W. H., Kwon, J. K., Shin, C., Lim, J. Y., Park, J. H., Huh, J. H., Kim, J. S., Kim, B. D., Cohen, O., Paran, I., Suh, M. C., Lee, S. B., Kim, Y. K., Shin, Y., Noh, S. J., Park, J., Seo, Y.S., Kwon, S. Y., Kim, H. A., Park, J.M., Kim, H. J., Choi, S. B., Bosland, P.W., Reeves, G., Jo, S. H., Lee, B. W., Cho, H. T., Choi, H. S., Lee, M. S., Yu, Y., Do Choi, Y., Park, B. S., van Deynze, A., Ashrafi, H., Hill, T., Kim, W. T., Pai, H. S., Ahn, H. K., Yeam, I., Giovannoni, J. J., Rose, J. K., Sørensen, I., Lee, S. J., Kim, R. W., Choi, I. Y., Choi, B. S., Lim, J. S., Lee, Y. H., and Choi, D. 2014. Genome sequence of the hot pepper provides insights into the evolution of pungency in Capsicum species. Nat. Genet. 46:270-278.

Kopelman, N. M., Mayzel, J., Jakobsson, M., Rosenberg, N., and Mayrose, I. 2015. Clumpak: A program for identifying clustering modes and packaging population structure inferences across K. Mol. Ecol. Resour. 15: 1179-1191.

Kousik, C. S., Sanders, D. C., and Ritchie, D. F. 1996. Mixed genotypes combined with copper sprays to manage bacterial spot of bell peppers. Phytopathology 86:502-508.

Kousik, C. S., and Ritchie, D. F. 1996. Disease potential of pepper bacterial spot pathogen races that overcome the Bs2 gene for resistance. Phytopathology 86:1336-1343.

Kousik, C. S., and Ritchie, D. F. 1998. Response of bell pepper cultivars to bacterial spot pathogen races that individually overcome major resistance genes. Plant Dis. 82:181-186.
Lee, D. H., Choi, H. W., and Hwang, B. K. 2011. The pepper E3 ubiquitin ligase RING1 gene, CaRING1, is required for cell death and the salicylic acid-dependent defense response. Plant Physiol. 156:2011-2025.

Li, H., and Durbin, R. 2009. Fast and accurate short read alignment with Burrows-Wheeler transform. Bioinformatics 25:1754-1760.

Li, H., and Durbin, R. 2010. Fast and accurate long-read alignment with Burrows-Wheeler transform. Bioinformatics 26:589-595.

Ma, X., Lewis Ivey, M. L., and Miller, S. A. 2011. First report of Xanthomonas gardneri causing bacterial spot of tomato in Ohio and Michigan. Plant Dis. 95:1584-1584.

Ma, X. 2015. Characterization and management of bacterial leaf spot of processing tomato in Ohio. Electronic Theses and Dissertation Center, Ohio State University, https://etd.ohiolink.edu/pg_10?0::NO:10:P10_ETD_ SUBID: 106812

Miller, S. A. 2012. Bacterial spot- A new old problem in the Midwest processing tomatoes. The Tomato Magazine 4-5.

NASS. 2017. National Agricultural Statistics Service. U.S. Department of Agriculture.

Nimmakayala, P., Abburi, V. L., Saminathan, T., Alaparthi, S. B., Almeida, A., Davenport, B., Nadimi, M., Davidson, J., Tonapi, K., Yadav, L., Malkaram, S., Vajja, G., Hankins, G., Harris, R., Park, M., Choi, D., Stommel, J., and Reddy, U. K. 2016. Genome-wide diversity and association mapping for capsaicinoids and fruit weight in Capsicum annuиm L. Sci. Rep. 6.

Obradovic, A., Jones, J. B., Balogh, B., and Momol, M. T. 2008. Integrated management of tomato bacterial spot. Pages 211-223 in: Integrated Management of Disease Caused by Fungi, Phytoplasma, and Bacteria, Integrated Management of Plant Pests and Diseases. A. Ciancio and K. G. Mukerji, eds. Springer Science+Business Media, Dordrecht.

Park, C.-H., Chen, S., Shirsekar, G., Zhou, B., Khang, C. H., Songkumarn, P., Afzal, A. J., Ning, Y., Wang, R., Bellizzi, M., Valent, B., and Wang, G.-L. 2012. The Magnaporthe oryzae effector AvrPiz-t targets the RING E3 ubiquitin ligase APIP6 to suppress pathogen-associated molecular pattern-triggered immunity in rice. Plant Cell 24:4748-4762.

Potnis, N., Timilsina, S., Strayer, A., Shantharaj, D., Barak, J. D., Paret, M. L., Vallad, G. E., and Jones, J. B. 2015. Bacterial spot of tomato and pepper: diverse Xanthomonas species with a wide variety of virulence factors posing a worldwide challenge. Mol. Plant Pathol. 16:907-920.

Pritchard, J. K., Stephens, M., and Donnelly, P. 2000. Inference of population structure using multilocus genotype data. Genetics 155:945-959.

R Core Team. 2016. R: A Language and Environment for Statistical Computing. R Foundation for Statistical Computing, Vienna, Austria.

Ritchie, D. F. 2007. Bacterial spot of pepper and tomato. The Plant Health Instructor. doi:10.1094/PHI-I-2000-1027-01

Romer, P., Jordan, T., and Lahaye, T. 2010. Identification and application of a DNA-based marker that is diagnostic for the pepper (Capsicum anпиит) bacterial spot resistance gene Bs3. Plant Breed. 129:737-740.

Rosenberg, N. A. 2004. DISTRUCT: A program for the graphical display of population structure. Mol. Ecol. Notes 4:137-138.

Schwartz, A., Potnis, N., Bart, R., Timilsina, S., Barak, J. D., Vallad, G. V., Jones, J. B., and Staskawicz, B. J. 2015. Phylogenomics of Xanthomonas field strains infecting pepper and tomato reveals diversity in effector repertoires and identifies determinants of host specificity. Frontiers in Plant Science, section Plant-Microbe Interaction, Research Topic titled "Genomics and Effectomics of the crop killer Xanthomonas". doi:10.3389/fmlcb.2015.00535

Stall, R. E., Jones, J. B., and Minsavage, G. V. 2009. Durability of resistance in tomato and pepper to xanthomonads causing bacterial spot. Annu. Rev. Phytopathol. 47:265-284

Tai, T. H., Dahlbeck, D., Clark, E. T., Gajiwala, P., Pasion, R., Whalen, M., Stall, R. E., and Staskawicz, B. J. 1999. Expression of the Bs2 pepper gene confers resistance to bacterial spot disease in tomato. Proc. Natl. Acad. Sci. USA 96:14153-14158.

Taranto, F., D’Agostino, N., Greco, B., Cardi, T., and Tripodi, P. 2016. Genomewide SNP discovery and population structure analysis in pepper (Capsicum апnиит) using genotyping by sequencing. BMC Genomics 17:943.

Troung, H., Kim, K., Kim, S., Cho, M., Kim, H., and Woo, J. 2011. Development of gene-based markers for the Bs2 bacterial spot resistance gene for marker-assisted selection in pepper (Capsicum spp.). Hort. Environ. Biotechnol. 52:65-73.

Tung, C.-W., Zhao, K., Wright, M. H., Liakat Ali, M., Jung, J., Kimball, J., Tyagi, W., Thompson, M. J., McNally, K., Leung, H., Kim, H., Ahn, S.-N., Reynolds, A., Scheffler, B., Eizenga, G., McClung, A., Bustamante, C., and McCouch, S. R. 2010. Development of a research platform for dissecting phenotype-genotype associations in rice (Oryza spp.). Rice 3:205-217.

Turner, S. D. 2014. qqman: An R package for visualizing GWAS results using Q-Q and Manhattan plots. bioRxiv 005165.

Üstün, S., and Börnke, F. 2014. Interactions of Xanthomonas type-III effector proteins with the plant ubiquitin and ubiquitin-like pathways. Front. Plant Sci. 5: 736. 
Van Dongen, S. 2000. Graph Clustering by Flow Simulation. PhD thesis, University of Utrecht, Utrecht, The Netherlands.

Wang, S., Durrant, W. E., Song, J., Spivey, N. W., and Dong, X. 2010. Arabidopsis BRCA2 and RAD51 proteins are specifically involved in defense gene transcription during plant immune responses. Proc. Natl. Acad. Sci. USA 107:22716-22721.

Wang, M., Yan, J., Zhao, J., Song, W., Zhang, X., Xiao, Y., and Zheng, Y. 2012. Genome-wide association study (GWAS) of resistance to head smut in maize. Plant Sci. 196:125-131.

Wang, C., Yang, Y., Yuan, X., Xu, Q., Feng, Y., Yu, H., Wang, Y., et al. 2014. Genome-wide association study of blast resistance in indica rice. BMC Plant Biol. 14:311. doi: 10.1186/s12870-014-0311-6

You, Q., Zhai, K., Yang, D., Yang, W., Wu, J., Liu, J., Pan, W., Wang, J., Zhu, X., Jian, Y., Liu, J., Zhang, Y., Deng, Y., Li, Q., Lou, Y., Xie, Q., and He, Z. 2016.
An E3 ubiquitin ligase-BAG protein module controls plant innate immunity and broad spectrum disease resistance. Cell Host Microbe 20:758-769.

Zhang, Z., Ersoz, E., Lai, C.-Q., Todhunter, R. J., Tiwari, H. K., and Gore, M. A., Bradbury, P. J., Yu, J.. Arnett, D. K., Ordovas, J. M., and Buckler, E. S. 2010. Mixed linear model approach adapted for genome-wide association studies. Nat. Genet. 42:355-360.

Zhang, H., Li, C., Davis, E. L., Wang, J., Griffin, J. D., Kofsky, J., and Song, B.-H. 2016. Genome-wide association study of resistance to soybean cyst nematode (Heterodera glycines) HG Type 2.5.7 in wild soybean (Glycine soja). Front. Plant Sci. 7.

Zhu, C., Gore, M., Buckler, E. S., and Yu, J. 2008. Status and prospects of association mapping in plants. Plant Gen. 1:5-20.

Zitter, T. A. 1985. Bacterial diseases of tomato. Bacterial Diseases Fact Sheet, Cornell Cooperative Extension 735.50. 